\title{
A Study of Chemical Content in Some Species of Tribe Apieae / Apiace
}

\author{
Zahra B. Muhammad \\ zahrabiology@gmail.com \\ Biology Deptment,College of \\ Education, Al-Haweja, University of \\ Kirkuk, Iraq
}

\author{
Talib O. Al-Khesraji \\ profdr.taliboh@tu.edu.iq \\ University of Tikrit, Iraq
}

\begin{abstract}
In this study, the flavonoid and alkaloid content in the alcoholic extract of the shoots and flowers were identified in four species of the tribe Apieae / Apiacese : Ammi majus, Ammi visgana, Anethum graveolens and Foeniculum vulgaris, and the flavonoids that were detected are (Apigenin, Coumarin, Kaempferol and Quercetin). The species Foeniculum vulgaris has recorded the highest concentration of total flavonoid content (Shoots and Flowers) among the studied species, reaching 4139.2 $\mu \mathrm{g} / \mathrm{ml}$. The total alkaloids are estimated for these species, and the Foeniculum vulgaris has recorded the highest concentration of the total alkaloid content as well.
\end{abstract}

Keywords: Apiaceae, Ammi, Apigenin, Coumarin, Alkaloid.

\section{Introduction}

The Apiaceae family is considered one of the most important families of flowering plants at the academic and practical levels, as its inflorescences had a great role in diagnosing them long before they are described scientifically for the first time [1] (Heywood,1976). Researchers disagreed about the number of genera and species belonging to this family, as [2] Lawrence (1951) indicated that it includes (200) genera and (2900) species. [3] Judd et. al (1999) indicated that this family is widespread and spreads in tropical to temperate regions and that it includes (400) genera and (4250) species.

In Iraq, this family is represented wildly by about (60) genera and (143) species [4] (A1Mousawi, 1987), while Al-Katib [5] (1988) indicated that there are (130) wild species and (9) cultivated species. [6] Ghazanfar and McDaniel (2016) also mentioned that this family is the fifth-largest plant family in Iraq and that it is represented by approximately (67) genera and (155) species.

The plants of this family contain many important chemical compounds that have contributed to strengthening their role as medicinal plants and a source of treatment for diseases, and the most important of these compounds are flavonoids [7] (Trovato et. al, 1996). This family is considered to be one of the most economically important families, as many of its species are used as food or flavorings such as the Foeniculum vulgare Mill., And Anethum graveolens L. In addition, many of the species are medicinal plants that have been used in the treatment of several medical conditions due to their containment of very important effective compounds such as essential oils, volatile oils, flavonoids, and alkaloids [8, 9] (Mutlag , 2007 and Al-Mayah, 2013). This family is considered to be a source of gum and perfumes, and a few of its species are used for decoration [4] (Al-Mousawi, 1987). 
A review of the available scientific sources revealed that the current study is the first local study in which the flavonoid and alkaloid contents of the four studied species are identified.

\section{Materials Method}

\subsection{Collection of Plant Specimens}

Fresh plant specimens are collected during the flowering stage and then marked with the necessary herbal information such as (place of collection, collector's name, the common name of the plant, and date of collection). These samples are dried and pressed with the aforementioned herbal information recorded. The taxonomic keys and the Iraqi flora / fifth volume are used for the diagnosis of the samples, and it is confirmed by comparing the collected samples with the herbal samples kept in the Kurdistan Botanical Foundation herbarium in Sulaymaniyah and the Iraqi national herbarium in Abu Ghraib.

\subsection{Chemical Study}

\subsubsection{Extraction of plant samples}

Liquid-liquid and solid-liquid extraction are the most commonly used procedures before analysis of Polyphenols and simple phenolic in natural plants. They are still the most widely used techniques, mainly because of their ease of use, efficiency, and wide-ranging applicability. Commonly used extraction solvents are alcohols (methanol, ethanol), acetone, diethyl ether, and ethyl acetate. The first steps of a preparation procedure are milling and homogenization. Extraction is the main step for the recovery and isolation of bioactive phytochemicals from plant materials, before analysis. It is influenced by their chemical nature, the extraction method employed, sample particle size, as well as the presence of interfering substances. Additional steps may be called for if the removal of unwanted phenolic and non-phenolic substances such as waxes, fats, terpenes, and chlorophylls is of interest. Thirty grams of plant powdered was extracted using $15 \mathrm{ml}$ chloroform with constant stirring for 24 hours at the ambient temperature. The extract was placed in an ultrasonic device for 15 minutes. Then $100 \mathrm{ml}$ of butanol was added and then transferred to the separation funnel. The polar organic layer (butanol) is collected and transferred to the rotary evaporator device to obtain a dry extractor. The operation is repeated (3) times to obtain an adequate amount before analysis.

\subsubsection{HPLC Condition for Analyzed Phenolic and Flavonoid Compounds}

Samples are analyzed by high-performance liquid chromatography HPLC model (SYKAM) Germany. Pump model: S 2100 Quaternary Gradient Pump, Autosampler model: S 5200, Detector: UV (S 2340), and Column Oven model: S 4115. The mobile phase was = (Methanol: D.W : acetic acid) (85: $13: 2)$, the column is C18-ODS (25 cm * $4.6 \mathrm{~mm})$ and detector UV $-360 \mathrm{~nm}$ at flow rate $1 \mathrm{ml} / \mathrm{min}$.

\subsubsection{Total Alkaloid Content}

The 20 gm of each plant material was ground and then extracted with methanol for 24 hours in a continuous extraction (Soxholet) apparatus. The extract was filtered and methanol was evaporated on a rotary evaporator under vacuum at a temperature of $45^{\circ} \mathrm{C}$ to dryness.

For more information about the Conference please visit the websites: 


\subsubsection{Qualitative Estimation (Test for Alkaloids)}

The presence of alkaloid was confirmed by Dragendroff's method. A part of the extract was dissolved in dilute HCL and 2 drops of Dragon drops are added, a crystalline precipitate indicates the presence of alkaloid. The sample which has shown positive alkaloid is then subjected to further quantitative evaluation.

\subsubsection{Separation of Alkaloid}

A part of the extract residue is dissolved in $2 \mathrm{~N} \mathrm{HCL}$ and then faltered. $1 \mathrm{ml}$ of this solution is transferred to a reparatory funnel and washed with $10 \mathrm{ml}$ chloroform. The $\mathrm{pH}$ of this solution is adjusted to neutral with $0.1 \mathrm{~N} \mathrm{NaOH}$. Then $5 \mathrm{ml}$ of Bromocresol Green (BCG ) solution and $5 \mathrm{ml}$ of phosphate buffer are added to this solution.

\subsubsection{Standard Carve}

Accurately measured aliquots $(0.4,0.6,0.8,1$, and $1.2 \mathrm{ml})$ of Atropine standard solution were transferred to different reparatory funnels. Then $5 \mathrm{ml}$ of $\mathrm{pH} 4.7$ phosphate buffer and 5 $\mathrm{ml}$ of BCG solution is taken and the mixture is shaken with extract with $1,2,3$, and $4 \mathrm{ml}$ of chloroform. The extracts are then collected in a $10 \mathrm{ml}$ volumetric flask and then have diluted to adjust the solution with chloroform. The absorbance of the complex in chloroform is measured at a spectrum of $470 \mathrm{~nm}$ in UV-Spectrophotometer (SHIMADZU UV-1800) against the blank prepared as above but without Atropine.

\section{Results and Discussion}

The results of the chemical study (Table 1) have shown the presence of four types of flavonoid compounds in the alcoholic extract of the shoots. These compounds are Coumarin, Catchine, Kaempferol, and Quercetin. The results of the chemical analysis have shown that the shoots are free of the flavonoid compound Apigenin.

The highest concentration of Coumarin in the shoots is $632.7 \mu \mathrm{g} / \mathrm{ml} \mathrm{in} \mathrm{F.vulgare,} \mathrm{and}$ the lowest concentration of this compound reached $402.0 \mu \mathrm{g} / \mathrm{ml}$ in A. visgana. As for the compound Catchine, the highest concentration reached $145.0 \mathrm{~g} / \mathrm{ml}$ in the type A. majus, while the species A.visgana recorded the lowest concentration of this compound, which is $105.4 \mu \mathrm{g}$ / ml. It should be noted that the concentrations of Kaempferol are similar in the four studied species, and its highest concentration is $39.7 \mathrm{~g} / \mathrm{ml}$ in species A.visgana, while the lowest concentration is $37.7 \mu \mathrm{g} / \mathrm{ml}$ in species A.majus, and the rest of the species has ranged between these values mentioned (Table 1). Regarding Quercetin, the highest concentration is $156.2 \mu \mathrm{g} / \mathrm{ml}$ in F. vulgare, and the lowest concentration is $51.7 \mu \mathrm{g} / \mathrm{ml}$ in A.visgana .

It is found from this study also that the flavonoid compound Coumarin is the highest concentration compound in the alcoholic extract of the shoot of all the studied species (Table 1). As for the total content of flavonoids in the alcoholic extract of the shoots in the studied species, the highest value of it is in the F.vulgare and reached $944.8 \mu \mathrm{g} / \mathrm{ml}$, while the lowest value for the total number of flavonoids is $598.8 \mathrm{~g} / \mathrm{ml}$ in the type A.visgana (Table 1).

Concerning the total content of flavonoids in the alcoholic extract of flowering inflorescences in the studied species (Table 2), the highest value of this total is recorded in F.vulgare as it is $3194.4 \mu \mathrm{g} / \mathrm{ml}$, while the lowest total value is $418.6 \mu \mathrm{g} / \mathrm{ml}$ in A.visgana. It is revealed through this study that only Apigenin and Coumarin are present in the alcoholic extract of the inflorescences (Table 2).

The species F.vulgare have shown the highest concentration of these two compounds

For more information about the Conference please visit the websites: 
(395.7 and 2798.7) $\mu \mathrm{g} / \mathrm{ml}$, respectively. The flavonoid compound Apigenin is absent from the flowers of A. majus. The lowest concentration of Coumarin is $313.2 \mu \mathrm{g} / \mathrm{ml}$ in A.visgana.

It should be noted that the species F.vulgare has recorded the highest concentration of compounds Apigenin, Catchine, Coumarin, and Quercetin for the whole plant (both the vegetative and flowering parts). Also, the species F.vulgare has the highest concentration of flavonoids in the vegetative and flowering parts, as it reaches $4139.2 \mathrm{~g} / \mathrm{ml}$, while A.visgana has the lowest concentration and reaches $1017.4 \mu \mathrm{g} / \mathrm{ml}$ (Table 3).

It is worth noting that coumarins are the most abundant flavonoids in the studied species, and this is in agreement with [3] (Judd et.al, 1999) who have indicated that coumarins are among the compounds most present in the plants of the Apiaceae family.

Table 1. Flavonoid concentrations measured in $\mu \mathrm{g} / \mathrm{ml}$ in the shoot parts of the studied species.

\begin{tabular}{|c|c|c|c|c|c|c|c|}
\hline no. & $\begin{array}{c}\text { Flavonoides } \\
\text { Sp. }\end{array}$ & Apigenin & Coumarin & Catchine & Kaempferol & Quercetin & total \\
\hline 1 & A.majus & 0 & 568.2 & 145.0 & 37.7 & 114.8 & 865.7 \\
\hline 2 & A.visgana & 0 & 402.0 & 105.4 & 39.7 & 51.7 & 598.8 \\
\hline 3 & A.graveolens & 0 & 468.4 & 130.5 & 38.2 & 98.7 & 735.8 \\
\hline 4 & F. vulgare & 0 & 632.7 & 116.5 & 39.4 & 156.2 & 944.8 \\
\hline & Total & 0 & 2071.3 & 497.4 & 155 & 421.4 & 3145.1 \\
\hline
\end{tabular}

Table 2. Flavonoid concentrations measured in $\mu \mathrm{g} / \mathrm{ml}$ in the flowering parts of the studied species.

\begin{tabular}{|c|c|c|c|c|c|c|c|}
\hline no. & $\begin{array}{c}\text { Flavonoides } \\
\text { Sp. }\end{array}$ & Apigenin & Coumarin & Catchine & Kaempferol & Quercetin & total \\
\hline 1 & A.majus & 0 & 527.7 & 0 & 0 & 0 & 527.7 \\
\hline 2 & A.visgana & 105.4 & 313.2 & 0 & 0 & 0 & 418.6 \\
\hline 3 & A.graveolens & 328.6 & 1482.7 & 0 & 0 & 0 & 1811.3 \\
\hline 4 & F. vulgare & 395.7 & 2798.7 & 0 & 0 & 0 & 3194.4 \\
\hline \multicolumn{2}{|c|}{ total } & 829.7 & 5122.3 & 0 & 0 & 0 & 5952 \\
\hline
\end{tabular}

Table 3. Total group of flavonoids (vegetative and flowering parts) measured in $\mu \mathrm{g} / \mathrm{ml}$ in each of the studied species.

\begin{tabular}{|c|c|c|c|c|c|c|c|}
\hline no. & $\begin{array}{l}\text { Flavonoides } \\
\text { Sp. }\end{array}$ & Apigenin & Coumarine & Catchine & Kaempferol & Quercetin & total \\
\hline 1 & A.majus & 0 & 1095.9 & 145 & 37.7 & 114.8 & 1393.4 \\
\hline 2 & A.visgana & 105.4 & 715.2 & 105.4 & 39.7 & 51.7 & 1017.4 \\
\hline 3 & A.graveolens & 328.6 & 1951.1 & 130.5 & 38.2 & 98.7 & 2547.1 \\
\hline 4 & F. vulgare & 395.7 & 3431.4 & 116.5 & 39.4 & 156.2 & 4139.2 \\
\hline \multicolumn{2}{|c|}{ total } & 829.7 & 7193.6 & 497.4 & 155 & 421.4 & 9097.1 \\
\hline
\end{tabular}

Regarding the total alkaloids, it is found from this study that the highest percentage of alkaloids in the shoot system is $7.2 \%$ in A.visgana, while A. majus recorded the lowest percentage, reaching 5.6\% (Table 4).

The highest percentage of alkaliod content recorded in the flowering system is in F.vulgare and is $16.2 \%$, while the lowest percentage recorded is $13.4 \%$ in A.visgana. It is evident from the observation of Table (4) that the species F.vulgare possesses the highest percentage of total alkaloid in the vegetative and flowering systems and of the studied species, which reaches $22.4 \%$, while the two species A.majus and A.visgana recorded the lowest total percentage, which is $20.6 \%$ for each.

The flowering system is higher in its total alkaloid content than the shoots of the species For more information about the Conference please visit the websites: 
under study, and the percentages are close in the studied species, which are few percentages and do not exceed $30 \%$ in one species, and perhaps these few percentages are the reason for the lack of interest of researchers in studying these important chemical compounds.

Table 4. Percentages of total alkaloids in shoots and inflorescents of the studied species.

\begin{tabular}{|c|c|c|c|c|}
\hline No & Sp. & Shoots \% & Inflorescents \% & Total \% \\
\hline 1 & A.majus & 5.6 & 15 & 20.6 \\
\hline 2 & A.visgana & 7.2 & 13.4 & 20.6 \\
\hline 3 & A.graveolens & 5.7 & 16 & 21.7 \\
\hline 4 & F. vulgare & 6.2 & 16.2 & 22.4 \\
\hline \multicolumn{2}{|r|}{} & 24.7 & 60.6 & 85.3 \\
\hline
\end{tabular}

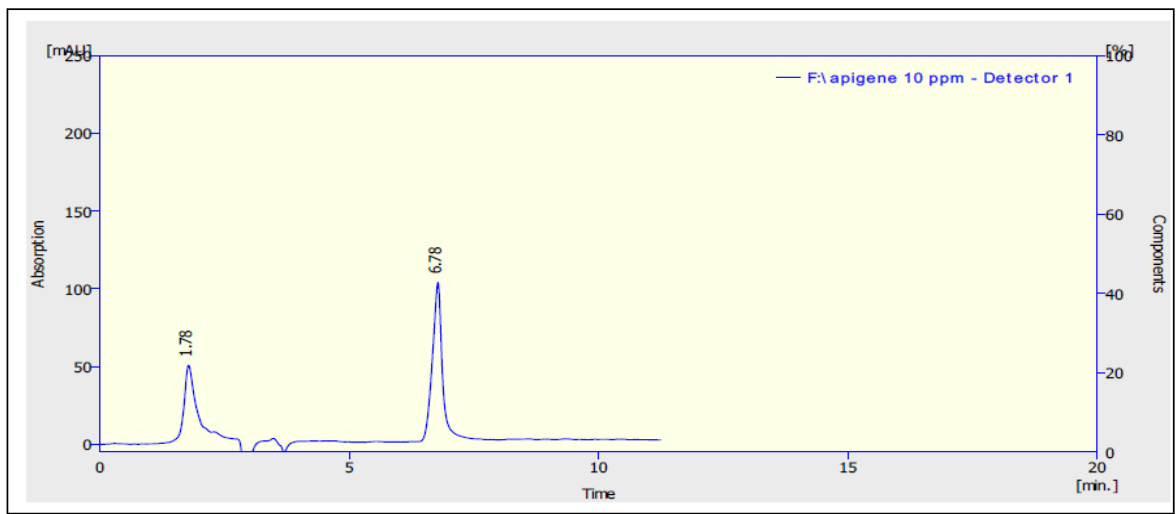

1

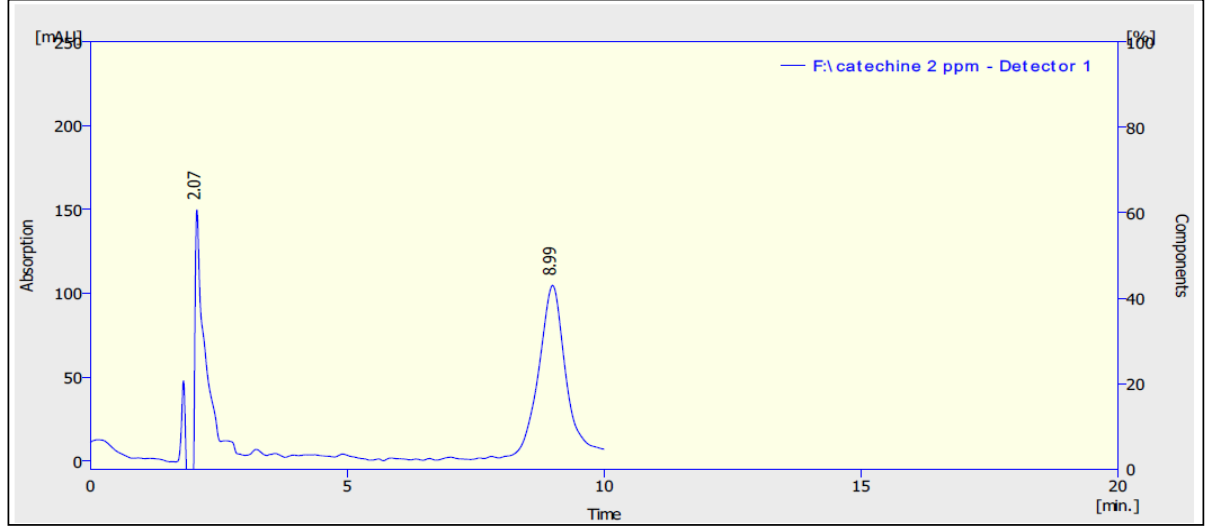

2

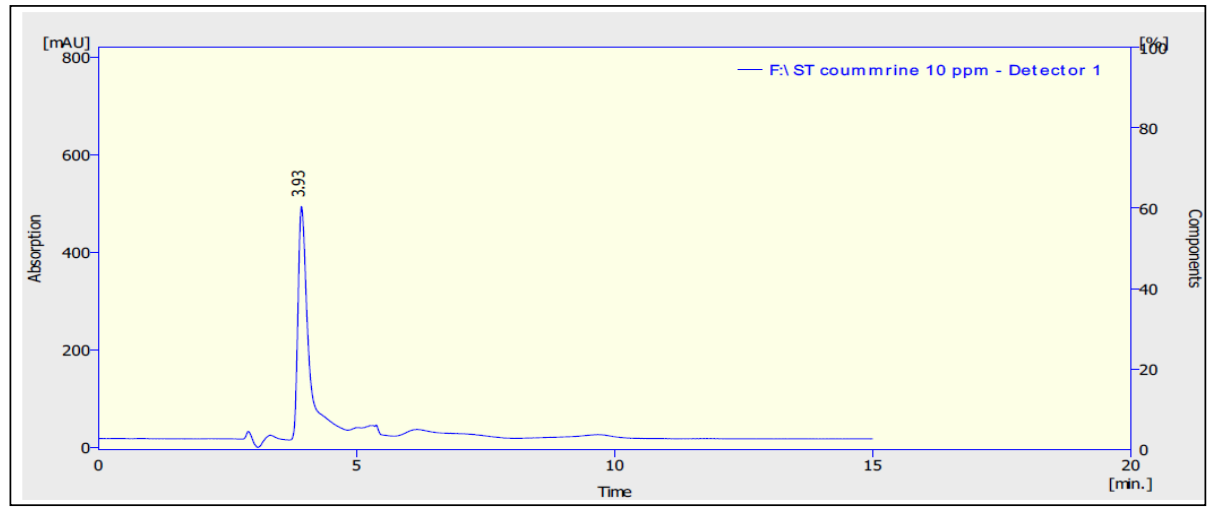

3

For more information about the Conference please visit the websites: 
Ibn Al-Haitham Journal for Pure and Applied science https://doi.org/10.30526/2021.IHICPAS.2647
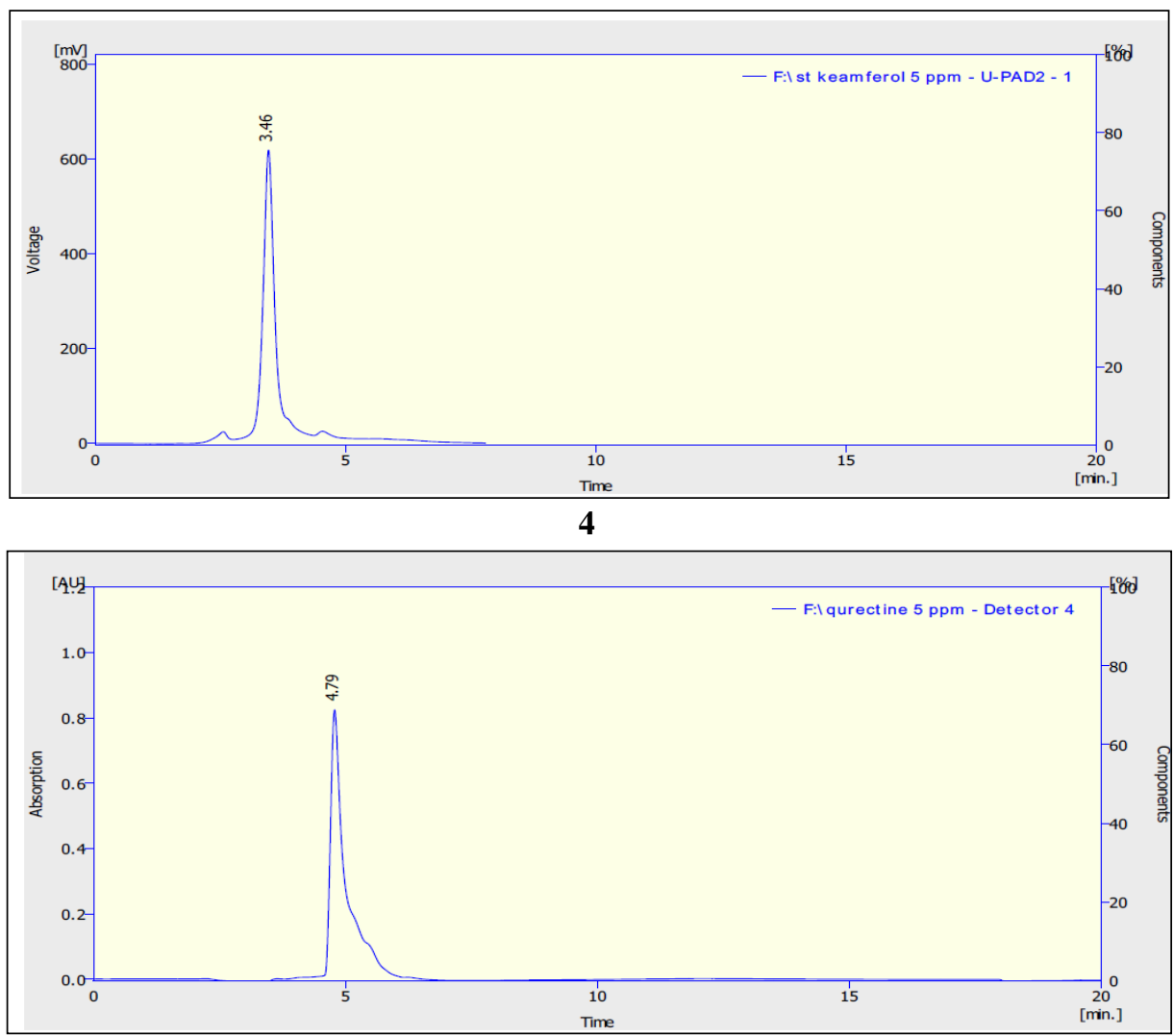

5

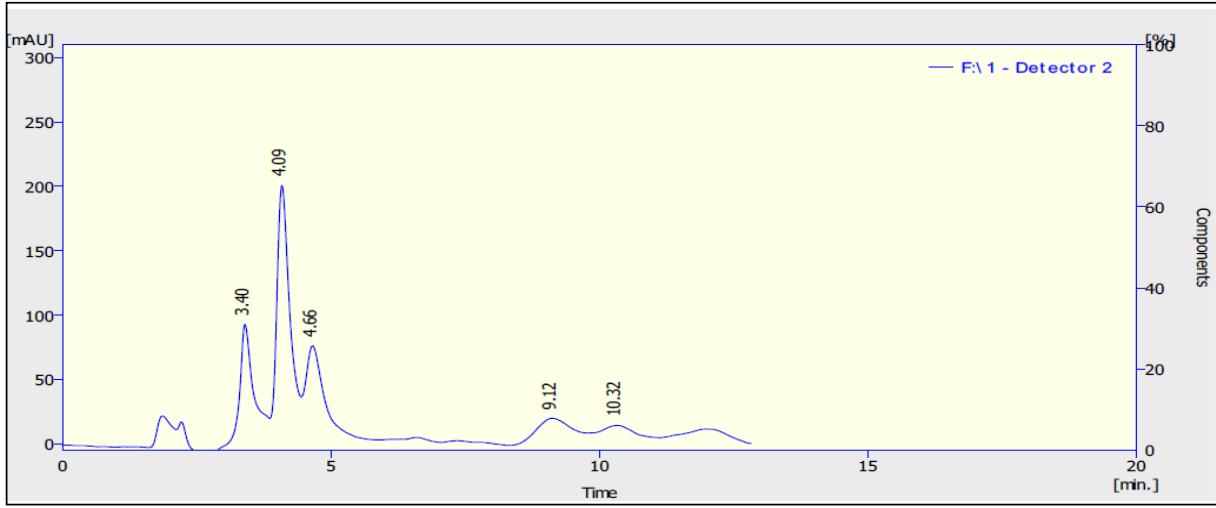

6a

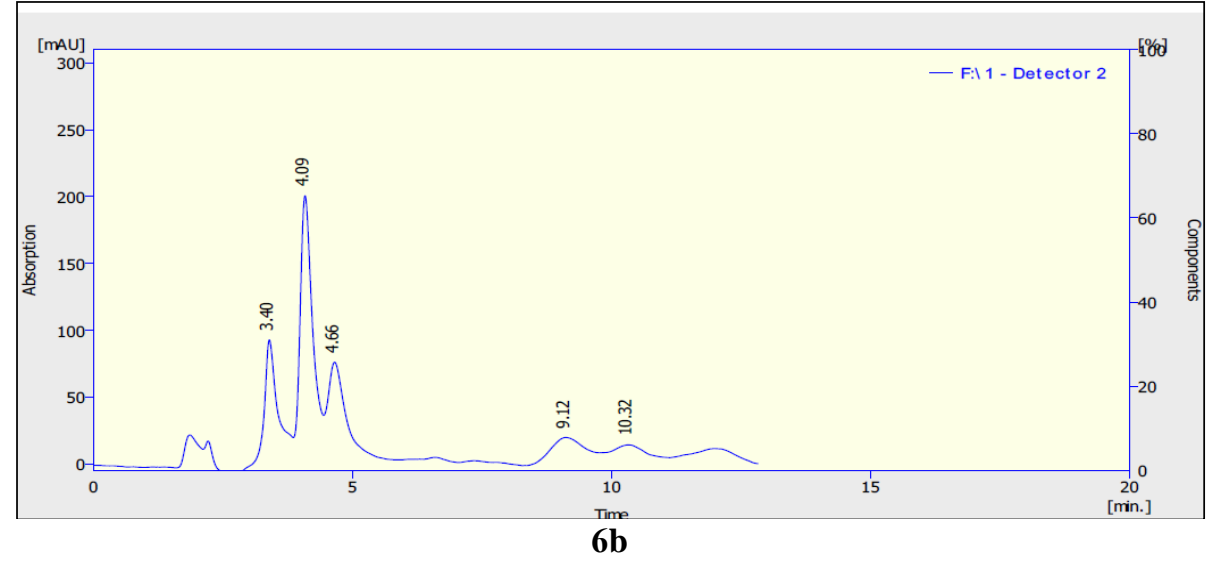

For more information about the Conference please visit the websites: 
Ibn Al-Haitham Journal for Pure and Applied science https://doi.org/10.30526/2021.IHICPAS.2647

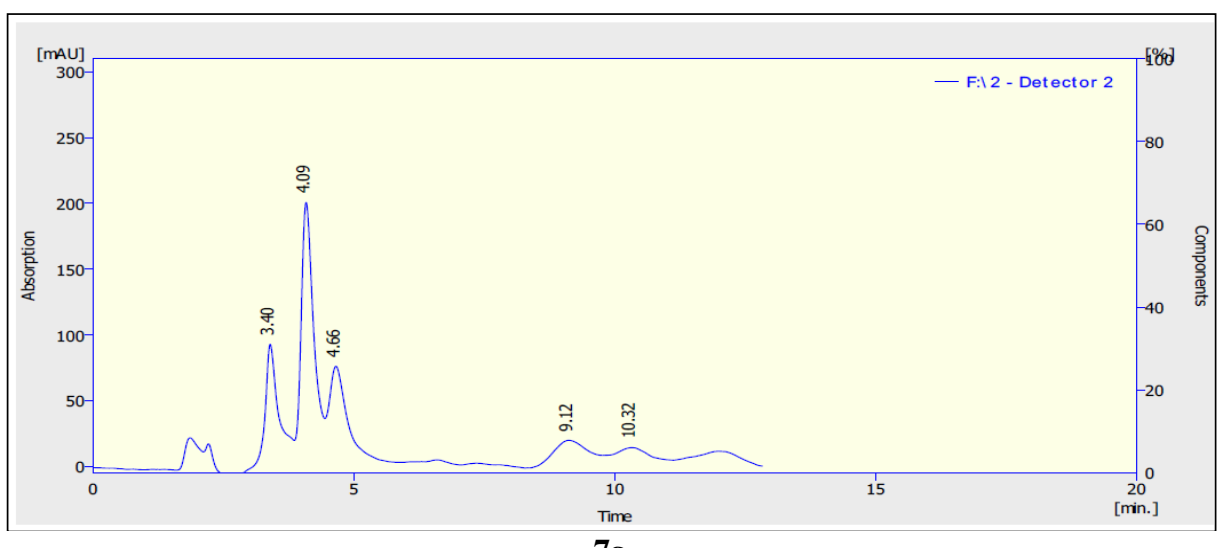

$7 \mathbf{a}$

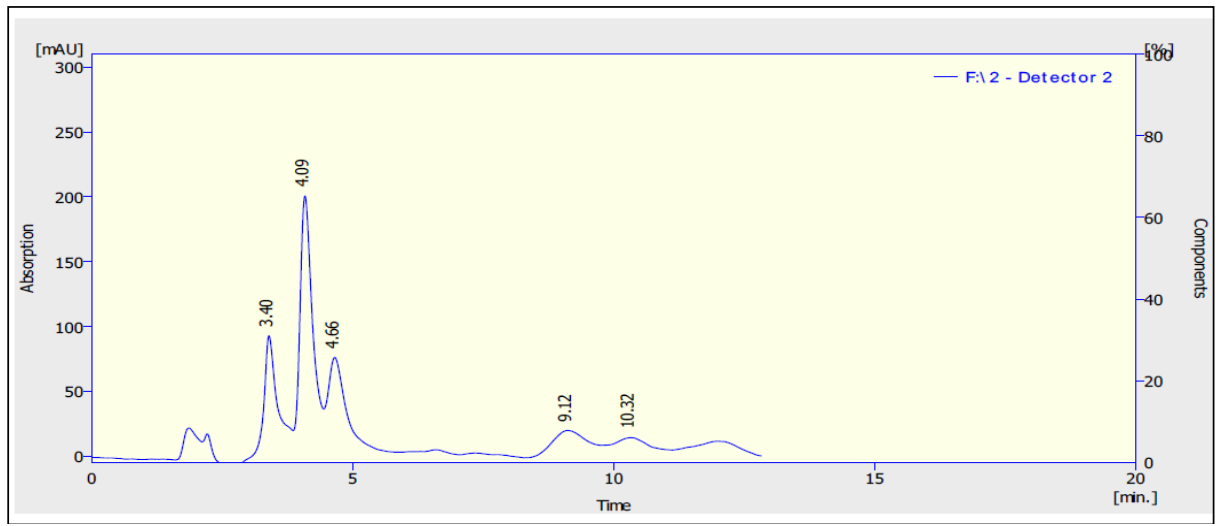

$7 \mathbf{b}$
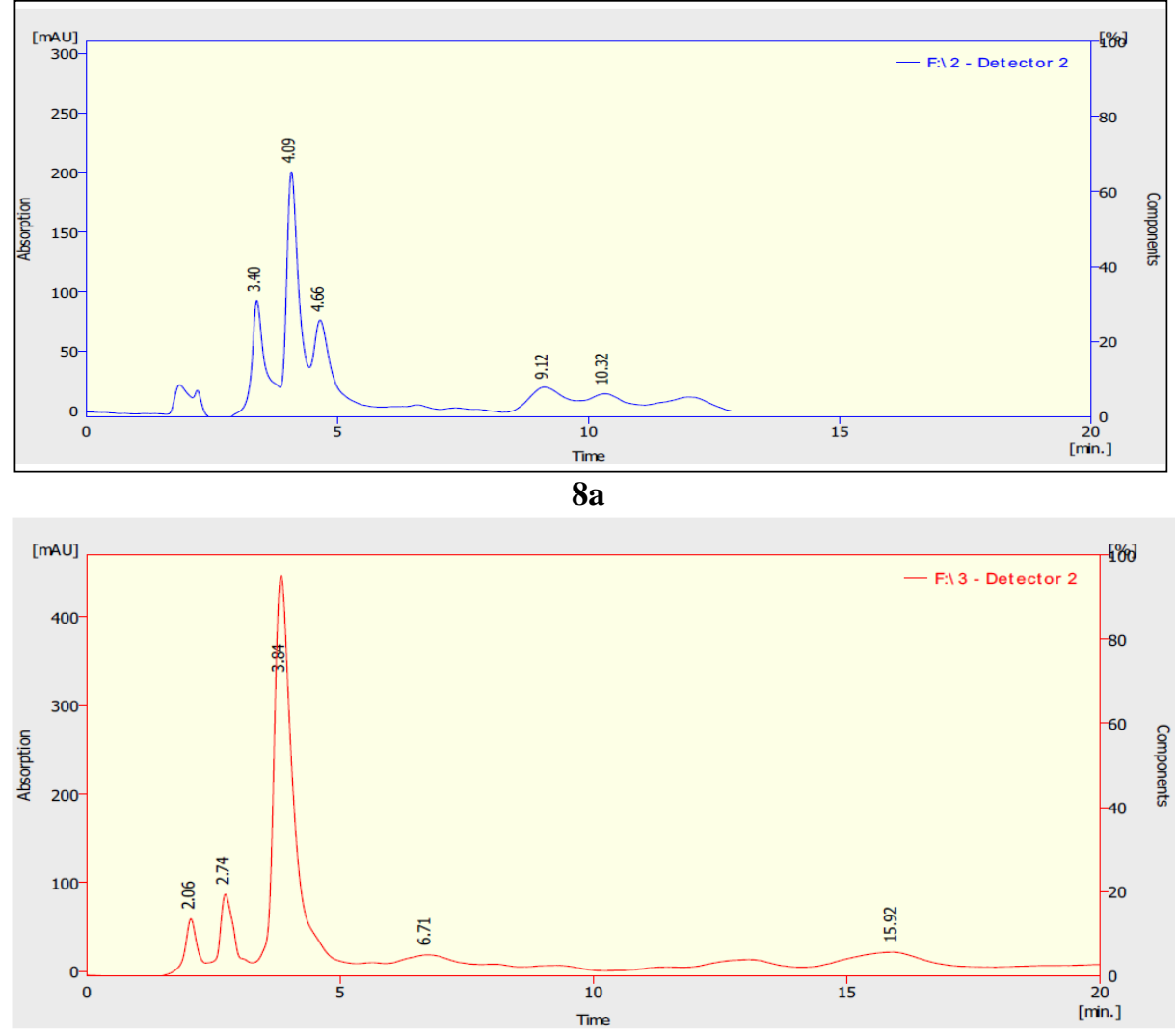

8b

For more information about the Conference please visit the websites: 
Ibn Al-Haitham Journal for Pure and Applied science https://doi.org/10.30526/2021.IHICPAS.2647
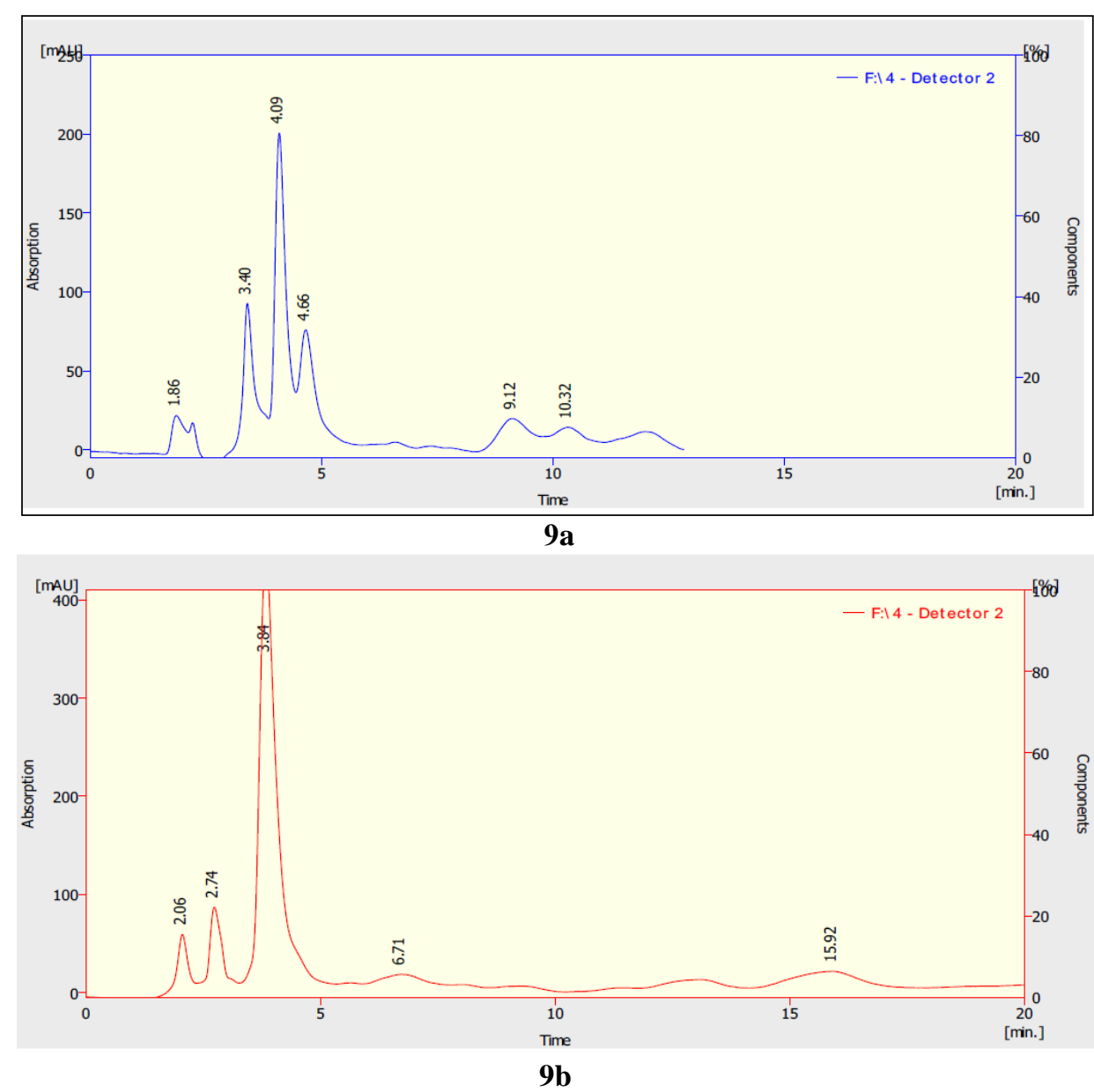

Figure 1. Standard curves of shoots and flowers extract of the studied species. (Standards: 1. Apigenin, 2. Catchine, 3. Coumarin, 4. Kaempferol, 5. Quercetine) (Species: a. shoot, b.flowers, 6. A.majus, 7. A.visgana, 8. A.graveolens, 9. F.vulgare).
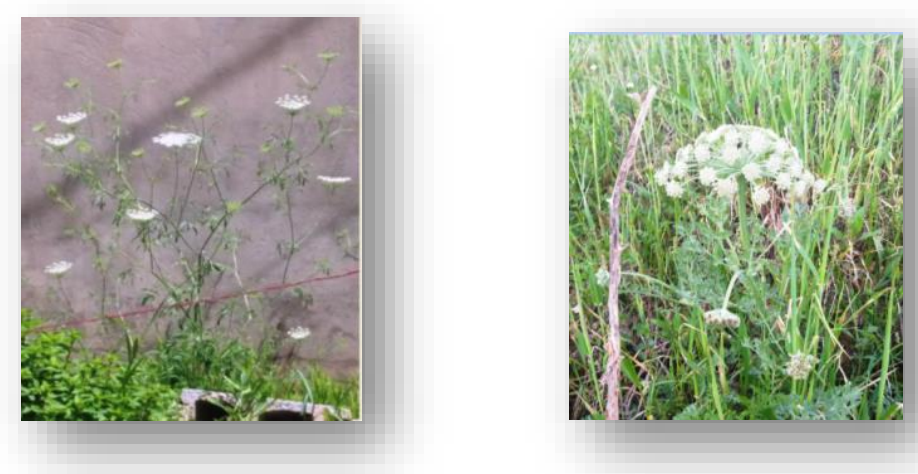

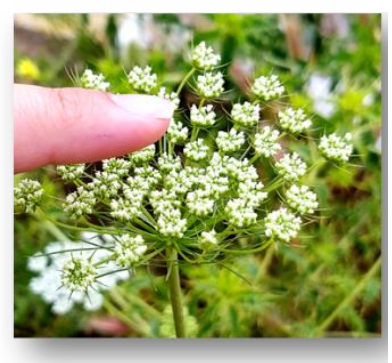

1

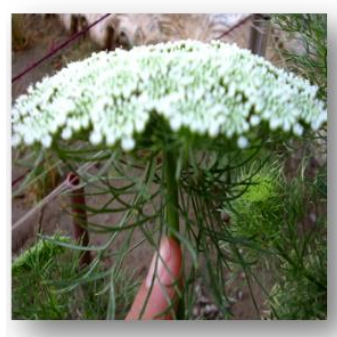

2

For more information about the Conference please visit the websites: 

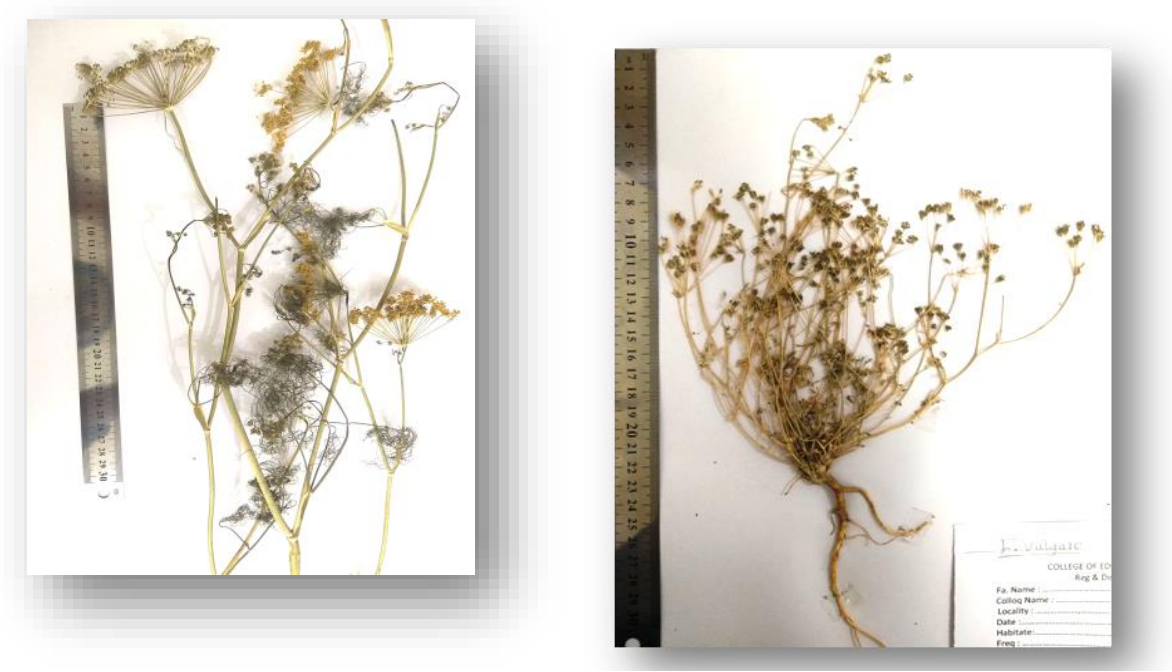

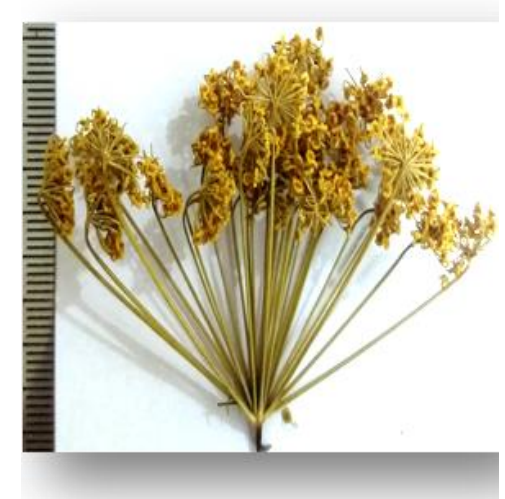

3

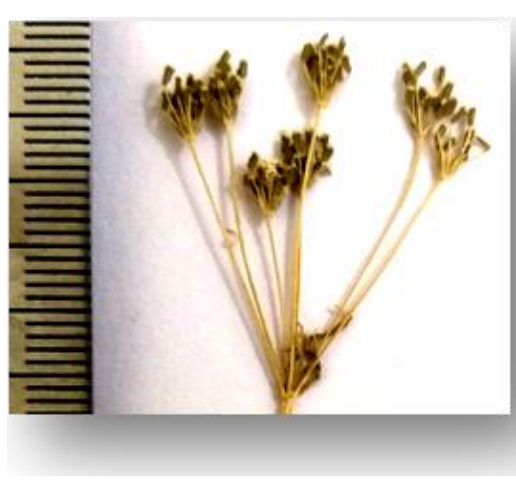

4

Figure 2. Studied species with their flowers: (1. A.majus , 2. A.visgana, 3.A.graveolens, 4.F.vulgare).

\section{References}

1. Heywood, V.H. Plant Taxonomy. $2^{\text {nd }}$ Ed. Edward Arnold 1976, London.

2. Lawrence, G.H.M. Taxonomy of vascular plants. The Macmillan Company. New York. 1951, 823.

3. Judd, W.S.; Campbell, C.S. Kellogg, E.A. ; Stevens, P.F. Plant systematics. Sinauer associates, Inc., Sunderland, Massachusetts, U. S. A. 1999, 464 .

4. Al-Mousawi, A.H. Plant Taxonomy. Books House for Printing and Publishing. University of Al Mosul 1987, 379.

5. Al-Katib. Y.M. Classification of seed plants. Baghdad University. Ministry of Higher Education and Scientific Research. Iraq 1988, p. 243.

6. Ghazanfar. S.A. and McDaniel. T. (2016) . Flora of the middle east : quantitative analysis biogeography of the flora of Iraq. Edinburgh J. Bot. $2016,73,1,1-24$.

7. Trovato. A.; Monforte. M.T.; Rossito. A.; Forestieri. A.M. In vitro cytotoxic effect of some medicinal plants containing flavonoids. Boll. Chim. Farm. 1996 , 135, 263-266.

8. Mutlag. S.H. Study of the Hepatoprotective effect of Ammi majus seeds extract in CCL4induced liver toxicity in rats.MSc.Thesis.University of Baghdad- College of pharmacy 2007, 90.

9. Al-Mayah. A.A. Medicinal plants and herbal remedies. Al-basaer Press. Beirut, Lebanon. 2013,358. 